\title{
El Muntu: la diáspora del pensamiento filosófico africano en Changó, el gran putas de Manuel Zapata Olivella*
}

Fecha de recepción: 12 de agosto de 2015

Fecha de aprobación: 30 de junio de 2016

\section{Resumen}

La problemática del fenómeno diaspórico en América es un elemento notable en Changó, el gran putas. En esta novela el éxodo africano se encuentra estrechamente relacionado con la filosofía Muntu. Esta filosofía agrupa unos saberes africanos compuestos de diversos elementos que resurgen en América transformándose dentro de un contexto de intercambio cultural postcolonial. En Changó, el Muntu nos permite analizar no solo la posibilidad de tejer una alianza africana y mestiza en pos de libertad en América, sino que constituye además una metáfora del mestizaje americano, una oportunidad de ver la Historia de este continente desde un punto de vista literario involucrando asimismo diferentes dimensiones del ser humano. Proponemos una reflexión en torno a la manera como las diferentes categorías filosóficas del Muntu (Kintu, Kuntu, Hantu y Muntu) son abordadas y ad[a/o]ptadas desde una perspectiva filosófico-literaria, cuestionando su relevancia dentro de la obra.

Palabras clave: África, Muntu, Kintu, Hantu, Kuntu, diáspora.

Citar: Sierra Díaz, D.C. (julio-diciembre de 2016). El Muntu: la diáspora del pensamiento filosófico africano en Changó, el gran putas de Manuel Zapata Olivella. La Palabra, (29), 23-44. doi: http://dx.doi.org/10.19053/01218530.n29.2016.5699

\section{Diana Carolina Sierra Díaz}

Université Bordeaux Montaigne. Magíster en literatura, Universidad Pedagógica y Tecnológica de Colombia. Magíster en estudios Hispánicos e Hispanoamericanos, Université Bordeaux Montaigne. carolinasierradiaz@gmail.com

* Artículo de reflexión, resultado de la investigación que la autora realizó para optar por el título de Magíster en Literatura de la Universidad Pedagógica y Tecnológica de Colombia. 


\section{la palabra}

\section{Muntu: the Diaspora of African Philosophical Thought in Changó, el gran putas [Changó, the Biggest Badass] by Manuel Zapata Olivella}

\section{Abstract}

The problem of diasporic phenomena in America is a significant element in Changó, el gran putas. In this novel, the African exodus is related to Muntu philosophy. This philosophy brings together African knowledges composed of diverse elements that reemerge in America, where they are transformed in a context of postcolonial cultural exchange. In Changó, Muntu philosophy allows us to analyze the possibility of creating an alliance between africans and mestizos committed to the freedom of America, at the same time as it becomes a metaphor for American mestizaje; an opportunity to see the History of this continent from a literary point of view which engages different dimensions of the human being. This study is a reflection about the way in which the different philosopical categories of Muntu (Kintu, Kuntu, Hantu and Muntu) are developed and ad[a/o]pted from a literary/philosophical perspective, inquiring into their relevance in the work.

Keywords: Africa, Muntu, Kintu, Hantu, Kuntu, diaspora.

\section{Le Mountou américain : la diaspora de la} pensée philosophique africaine dans Chango, el gran putas [Changó, ce sacré dieu] de Manuel Zapata Olivella

\section{Résumé}

Le phénomène de diaspora aux Amériques est un élément central dans Changó, ce sacré dieu. Dans ce roman, l'exode africain est lié à la philosophie Mountou. Cette philosophie regroupe des connaissances africaines composées de divers éléments qui resurgissent aux Amériques et se transforment dans un contexte d'échange culturel postcolonial. Dans Changó, le Mountou nous permet d'analyser non seulement la possibilité de tisser une alliance africaine et métisse qui permettrait la liberté aux Amériques mais encore le fait qu'il constitue une métaphore du métissage américain. Le Mountou est une opportunité de voir l'Histoire de ce continent d'un point de vue littéraire qui rassemble différentes dimensions de l'homme. Nous nous demandons comment les différentes catégories philosophiques du Mountou (Kintou, Kountou, Hantou et Mountou) sont abordés et ad[a/o]ptés dans une perspective philosophique et littéraire et quelle seraient leurs contributions dans l'œuvre.

Mots-clés : Afrique, mountou, kintou, hantou, kountou, diaspora. 
Médico, folclorista, escritor e intelectual colombiano, también conocido en Latinoamérica como "el decano de la literatura negra", y considerado además como uno de novelistas más importantes de la literatura "afrocolombiana" del siglo XX, Manuel Zapata Olivella (1920-2004) recrea en su novela Changó, el gran putas ${ }^{3}$ la perspectiva histórico-social de los africanos en Colombia y en América. De este modo, su creación literaria se sensibiliza particularmente con la problemática de la trata de los africanos esclavizados, el racismo y la lucha por la igualdad de derechos civiles. Changó ${ }^{4}$, fruto de veinte años de investigación, así como de diversos viajes del autor, es considerada como la obra más importante de Zapata Olivella. La presente reflexión tiene como objetivo central examinar la filosofía Muntu ${ }^{5}$ y la manera como esta es dilucidada en Changó, el gran putas. Para ello, proponemos un análisis a partir de las cuatro categorías del Muntu: Kintu, Hantu, Kuntu y Muntu. ¿En qué medida se relacionan la diáspora y el Muntu en la novela? ¿En qué consiste la filosofía Muntu? ¿Cuál es su relación con el contexto literario de la novela? ¿A partir de qué elementos literarios podemos percibir sus categorías en Changó? ¿Qué otras posibilidades de percepción literaria nos brindan el análisis de la obra desde estas perspectivas? Proponemos una reflexión en torno a la manera como las diferentes categorías filosóficas del Muntu (Kintu, Kuntu, Hantu y Muntu) son abordadas y ad[a/o]ptadas desde una perspectiva literaria, cuestionando su relevancia dentro de la obra. Este artículo hace parte de la investigación: "La commun-ication dans Changó, el gran Putas".

En Changó, Zapata Olivella se acerca a la cosmovisión yoruba y sus orichas. Al respecto mencionaremos la investigación de Nellys Montenegro de la $\mathrm{Hoz}$ (2012) quien ha explorado conceptos como el de "africanía", sosteniendo que en Changó: "prevalece la preocupación de Zapata Olivella por la identidad Africana de los pueblos del caribe, preocupación manifestada a través de su historia, reflejo del patrimonio inmaterial ligado a la vida espiritual y material del negro y esclavo africano" (p. 80). Dentro de este marco de identidad africana, es posible resaltar que la novela de Zapata Olivella no solo intenta construir la identidad de los pueblos afrodescendientes del caribe sino también la de las comunidades afro presentes

1 En Tillis, A. (2008). Afro-Hispanic Literature in the US: Remembering the Past, Celebrating the Present, and Forging a Future. IPOTESI, p. 25.

2 El término aparecerá entre comillas, pues consideramos que su aplicación dentro del ámbito de la literatura colombiana es aún confuso. En este artículo proponemos e interpretamos el uso de la categoría "literatura afrocolombiana" como la literatura colombiana de temática afro, para los casos de obras literarias como la de Zapata Olivella, donde se encuentra un vínculo con las tradiciones culturales o ancestrales africanas. Consideramos el espacio de "literatura afrocolombiana" dentro de este marco de ideas, lo cual nos llevaría a un género literario particular de la literatura colombiana, mas no a crear juicios de orden étnico. Para los autores afrodescendientes, que escriben sobre diversos temas, planteamos simplemente literatura colombiana, entendiendo esta última como una amalgama que acoge a cualquier escritor colombiano de cualquier origen étnico. Por otra parte, subrayamos el hecho que ser "afro-descendientes", "hispano-descendientes", o "indígena-descendientes" no excluye a estos autores de su condición esencial de colombianos. Investigaciones como las de Silvia Valero han tratado de examinar la problemática de la "literatura afrocolombiana"; ver Valero, S. ¿De qué hablamos cuando hablamos de "literatura afrocolombiana"?. Estudios de Literatura Colombiana, pp. 15-37.

3 Publicada inicialmente por la editorial colombiana Oveja Negra en 1983 y 1985, posteriormente, la editorial Rei Andes Ltda. publicaría la primera edición crítica a cargo de Dorita Piquero de Nouhaud en 1992. En 2007, el Grupo Educar la incluye dentro de su colección "Espacio de Leer", y su más reciente edición aparece en 2010 dentro de la Biblioteca de Literatura Afrocolombiana, creada por el Ministerio de Cultura de Colombia. Ha sido traducida al francés por Dorita Piquero (Chango, ce sacré dieu edición Miroirs 1991) y al inglés por Jonathan Tittler (Changó, the biggest badass, 2010).

4 De esta manera designaremos la novela de ahora en adelante. En letra cursiva haremos referencia a la novela, y en letra normal a Changó, el oricha de los truenos, la virilidad, la guerra, la danza y el fuego.

5 El Muntu es el nombre con el cual se reconoce esta filosofía africana, pero es a la vez una de sus categorías. En este artículo nos referiremos al Muntu-categoría en letra cursiva (Muntu), y a la filosofía Muntu en letra normal. 
en toda América. Por ello, en la obra encontramos una construcción estética que hace referencia frecuente a los elementos que constituyen dicha africanía. Así, vemos que Changó, dios guerrero, oricha de los truenos, de la virilidad, la danza y el fuego, condena a un numeroso grupo de africanos al exilio y la esclavización en América. Para ellos, el desafío consiste en luchar por obtener su libertad de nuevo, arraigándose profundamente a los orishas y a la filosofía del Muntu. El éxodo de los africanos y su posterior rebelión contra la opresión colonizadora, y sus efectos, constituyen las cinco partes que componen la novela: "Los orígenes", "El Muntu Americano", "La rebelión de los vodús", "Las sangres encontradas" y "Los ancestros combatientes". Para esto, el tiempo referencial histórico de la novela se ubica inicialmente en el siglo XVI con la trata africana, y finaliza en el siglo XX dentro del marco de la lucha por la igualdad de los derechos civiles para los afrodescendientes en Estados Unidos.

La diáspora es un elemento significativo dentro del proceso de llegada del Muntu a América. En el diccionario de estudios culturales latinoamericanos, $\mathrm{Xi}$ mena Briceño y Debra Castillo la definen como una "población que forzosamente debe dejar su patria tradicional para sepa- rarse y diseminarse por otras partes del mundo" (Irwin \& Szurmuk, 2009, p. 85). Briceño y Castillo mencionan, además, que esta migración forzada es un elemento que transforma el territorio al que llegan estas poblaciones. Dentro de este marco de ideas, comprenderemos la diáspora africana en la novela, como un umbral cultural que transforma la cosmovisión tanto de los africanos como de la sociedad latinoamericana en la cual se encuentran inmersos.

El Muntu es la filosofía africana que fundamenta la estructura de Changó. Este concepto contempla la coexistencia de seres humanos, animales, plantas, minerales y los objetos que sirven al hombre. Sobre el Muntu, Mina (2003) sostiene que "hay una interacción siempre presente entre todos los reinos y las criaturas de la tierra, que se extiende a aquello que no alcanzamos a percibir" (p. 133). Rescataremos como rasgo considerable la interrelación de los diferentes componentes de esta filosofía, puesto que Zapata Olivella le asigna un valor especial en la estructuración de su novela, entrecruzando la historia y la literatura a través de las categorías Kintu, Kuntu, Hantu y Muntu, como veremos más adelante.

El término Muntu se encuentra relacionado con la comunidad lingüística Bantú en África.
Los bantúes constituyen un conjunto numeroso de grupos étnicos y de diversas lenguas provenientes de países como Angola, Camerún, República Democrática del Congo, Kenia, Mozambique, Sudáfrica, Uganda y Zimbabue, entre otros. Placide Tempels, autor de Filosofía bantú (1945), examina en su obra la manera como las lenguas bantúes se aproximan, señalando asimismo las semejanzas de las sociedades que las conforman tanto como de sus costumbres. La "filosofía bantú" o "filosofía Muntu" hace referencia al mismo concepto. Mientras que Placide Tempels se refiere a la "filosofía bantú", otros expertos como Jahnheinz Jahn o Fabien Eboussi Boulaga deciden simplemente llamar a esta "filosofía Muntu".

El Muntu como fuerza vital es uno de los puntos en común entre Tempels; Jahn y Kagame. En Filosofía bantú, Tempels aborda temas como la vida y la muerte, el culto al ser supremo y la ontología de los bantúes. Posteriormente, Janheinz Jahn y Alexis Kagame hablarán de una filosofía Muntu, constituida por las categorías Kintu, Kuntu, Hantu y Muntu. Dentro de este contexto, se considera el Muntu como una categoría que hace referencia al hombre, el Kintu a los animales tanto como los objetos, el Hantu a las categorías de tiempo y espacio, y, fi- 
nalmente, el Kuntu se refiere a la forma de ser, al estilo y a la belleza ${ }^{7}$. Respecto a las categorías del Muntu, Jahn afirma que "fuera de ellas no hay nada imaginable" (Janheinz, 1963, p. 137).

No nos cabe duda de que el Muntu posee un rol significativo y privilegiado dentro de la narración de Changó; y si bien es cierto que en la novela no aparecen referencias concretas al Kintu, Hantu o Kuntu como tal, este artículo explorará la manera en que Zapata Olivella las utiliza en su narración de una manera indirecta a partir de los rasgos que cada una de ellas supone dentro del campo filosófico africano. Nos es posible pensar que Zapata Olivella está al tanto de los diferentes componentes del Muntu, puesto que, en la sección final de la novela, presenta un "Cuaderno de Bitácora, mitología e historia" donde dilucida el concepto de la siguiente manera:

Bantú: Plural de muntu, hombre. El concepto implícito en esta palabra trasciende la connotación de hombre, ya que incluye a los vivos y difuntos, así como a los animales, vegetales, minerales y co- sas que le sirven. Más que entes o personas, materiales o físicos, alude a la fuerza que une en un solo nudo al hombre con su ascendencia y descendencia inmersas en el universo presente, pasado y futuro. (Zapata Olivella, 2010, p. 648).

Desde el inicio de la novela, Zapata Olivella resalta el valor del Muntu ubicándolo en el íncipit: “¡Oídos del Muntu, oíd!” (Zapata Olivella, 2010, p. 42). Encontramos aquí a unos narratarios representados mediante la personificación de los Oídos del Muntu, quienes según las costumbres africanas conservarán el saber de generación en generación mediante la palabra, renovando el compromiso de hacer perdurar esta filosofía de generación en generación. Esta frase de ataque con que inicia la novela provoca en el lector el deseo de saber más sobre el Muntu adentrándose en el viaje que supone la lectura de Changó.

A partir de este panorama, formularemos las siguientes preguntas: ¿Qué elementos nos permiten establecer la presencia del Muntu, Kintu, Hantu y Kuntu en la novela? ¿De qué manera Zapata Olivella los adopta y transforma en su narración? ¿Qué relevancia tiene el Muntu en Changó? Para dar respuesta a estos interrogantes, proponemos acercarnos al Muntu en la novela, abordando separadamente cada una de sus categorías, guiándonos principalmente por los postulados de Tempels, Jahn, y Kagame. Observaremos que Zapata Olivella no solo plasma estas categorías en su novela, sino que además las moldea y las adapta, renovándolas en un contexto ajeno al de su origen, y otorgándoles una nueva posibilidad de vida mediante la literatura. A continuación, comenzaremos describiendo los elementos ligados al Kintu en Changó.

\section{Kintu}

Si bien es cierto que Tempels no desarrolla la filosofía Bantú proponiendo categorías específicas, es posible afirmar la referencia que él hace al Kintu mencionándolo bajo su forma plural "Bintu". Tempels (2013) explica que el Bintu comprende 'las cosas', y aquellas fuerzas ${ }^{8}$ que no poseen raciocinio (p. 36). Por su parte, Jahn (1963) afirma que el Kintu hace referencia a "los animales, las plantas, los minerales y cualquier cosa ina-

\footnotetext{
$7 \quad$ Las definiciones de estas categorías a partir de Jahn y Kagame son breves, y un tanto limitadas a nuestro parecer, dada la profundidad y complejidad de cada uno de estos ejes filosóficos. En este sentido, mencionaremos que el debate contemporáneo en torno a estas categorías, se ha quedado en las definiciones presentadas en los años 1950s sin ser complementadas por nuevos aspectos.

8 Para Tempels, Jahn y Kagame, la «fuerza» es una de las características principales de las categorías del Muntu.
} 
nimada entra en esta categoría"9 (p. 20). Otros aportes similares como el de John Mbiti en African Religions and Philosophy sostienen que el Kintu contiene las fuerzas (animales y plantas) que no actúan por sí solas, sino bajo la influencia del Muntu (Mbiti, 1969, p. 11). Los conceptos hasta aquí mencionados sobre el Kintu, nos permiten tener una base para aproximarnos a Changó, teniendo en cuenta las características que estas definiciones tienen en común.

En Changó, estudiaremos el Kintu examinando tres grandes elementos básicamente: la tierra, las plantas y los animales. Dentro de este orden de ideas, señalaremos particularmente un vínculo fuerte con los árboles, acentuando específicamente la relación con el Baobab. Por otra parte, observaremos que los animales, por ejemplo, las serpientes, también se encuentran presentes en la novela operando desde diferentes perspectivas. A continuación, examinaremos la manera como la construcción simbólica de las serpientes se encuentra ligada a la rebeldía. De este modo, nos detendremos en algunos pasajes de la novela que desarrollan esta categoría.

El árbol de baobab es un elemento que palpita a lo largo de la narración de Changó. Su nombre científico es "Adansonia digitata", y es también conocido como árbol botella. Este árbol se encuentra principalmente en las zonas semiáridas del África y puede alcanzar a vivir más de mil años. En algunos lugares de África, es comúnmente denominado como “el rey de los árboles", debido a todas las virtudes que de él provienen y por otras de orden místico. La relación entre Baobab y la sociedad africana se teje en torno a una práctica ancestral que constituye un lugar de encuentro denominado comúnmente el "arbre à palabre" ('árbol para palabrear / charlar'), un espacio para discutir sobre la política y la sociedad. Zapata Olivella (2002) enmarca la presencia del Baobab dentro de un contexto que une a los africanos con su vida ancestral:

Justificado está que al memorizar la llegada del Muntú africano a la América con sus múltiples etnias e idiomas, enmarquemos su creatividad y hechos en torno a las raíces y ramificaciones del Árbol de la palabra, morada de los orichas y ancestros. Una amplia geografía que está demarcada por los pasos andados en la vida y la memoria ancestral colec- tiva de sus descendientes. (p. 93).

El escritor colombiano retoma el baobab mencionándolo en varios pasajes de Changó: "Ya bajas por las cuatro esquinas/ por las ramas/ por el tronco ancho del baobab. / Elegba ${ }^{10}$, guardián de los puertos ayúdame a retener el nudo/ el momento de la partida" (Zapata Olivella, 2010, p. 76). La cita es tomada de la primera parte de la novela, donde hay una serie de poemas entre los que encontramos uno titulado "La despedida, Bienvenida a Elegba abridor de las puertas". Allí, observamos a Ngafúa, un ancestro africano que también partirá en una nao rumbo a América. El pasaje evoca a Elegba, el oricha "abridor de caminos" antes de emprender al viaje que conducirá a los africanos a América. Percibimos aquí el árbol, como un mediador y un testigo que favorece la conexión entre los humanos y los orichas, idea que nos permitirá plantearlo como una fuerza relacionada al Kintu, ya que en torno a él suceden hechos trascendentales de orden espiritual. Ngafúa, junto al Baobab, invoca a Elegba con el fin de que este le dé el don de la palabra pidiéndole, además, que no cierre las puertas a los africanos que parten al exilio.

\footnotetext{
$9 \quad$ Texto original: "animals, plants, minerals and any unanimated thing fall within this category". Traducción por la autora del artículo.

10 También denominado en la novela como Legba, Elegúa, Eshú y Exú.
} 
Una nueva evocación del baobab aparece en el suceso más sobresaliente del primer capítulo de la segunda parte del libro: la coronación de Benkos Biohó ${ }^{11}$ como rey de los africanos, suceso que transcurre en Cartagena. Al respecto, Montenegro (2014) sostiene que:

Benkos representa al joven devoto a quien le era permitido ser sacristán en los bautizos, testigo en los matrimonios y acompañante del padre Claver en sus predicaciones. Sin embargo, este niño es el elegido para enfrentar a los colonizadores y restaurar la identidad de su etnia (p. 63).

Dentro de este contexto, observamos que para la proclamación de Benkos hay una serie de rituales africanos que el babalao ${ }^{12}$ realiza, entre ellos, la consagración del nuevo rey a Elegba. Dicha celebración se lleva a cabo frente a una comunidad heterogénea de africanos, algunos provenientes de Calabar, Cabo Verde y el Congo (Zapata Olivella, 2010, p. 173). En este escenario, encontramos en el baobab un elemento que aproxima al hombre, a la naturaleza y sus creencias: "Los ancianos rememoran y sus lágrimas son caminos húmedos que retornaban, madre África, a tu seno. En otras noches bajo el baobab sagrado también ellos fueron consagrados a Elegba" (Zapata Olivella, 2010, p. 172). La cita anterior nos confirma, además, que, para los africanos de Changó, existe un nexo directo entre el baobab y Elegba, subrayando la importancia de este en los rituales de consagración a los orichas. Encontramos, asimismo, otros elementos de orden natural como las lágrimas de los ancianos; una suerte de materialización de la nostalgia, ligada tanto a la ausencia del baobab, como a su rol característico de las ceremonias africanas.

En el tercer capítulo de la segunda parte de la novela, hallamos otra mención al baobab. Esta vez, la Inquisición vendrá persiguiendo al babalao por practicar cultos no aceptados por la corona española. Los inquisidores llegarán en búsqueda del babalao en la noche, advirtiendo con extrañeza que los africanos no durmieran en ese momento:

Cuando llegaron a la plaza de la Yerba nadie duerme porque en la noche oscura el muntu gustaba de evocar a sus ancestros. En otras noches, allá en la tie- rra natal, en vez de rememorar en silencio conversaríamos con los difuntos bajo el baobab de la aldea; en vez de estar sentados, bailamos; en vez de fumar tabacos, beberemos salmirón. (Zapata Olivella, 2010, p. 212).

Observamos en esta cita el árbol como un espacio propicio de intercambio entre vivos $y$ difuntos, involucrando una dimensión mística que abordaremos más adelante cuando estudiemos el Muntu. En la novela, el Kintu representado por el baobab y su ausencia del baobab en América, evidencia ciertos fenómenos relacionados con la melancolía. Este sentimiento de falta es manifestado en el plano físico mediante las lágrimas y el silencio. Estas dos manifestaciones connotan la irrupción opresora tanto como la impotencia que experimentan con frecuencia los africanos bajo la presión de los colonizadores y negreros.

Nos ocuparemos ahora del estudio de otro aspecto relacionado con el Kintu en la novela: las serpientes. Este reptil, símbolo de la sabiduría, la salud y la eternidad, presente en diversas culturas, desempeña un papel importante en Changó. En este

\footnotetext{
11 Líder cimarrón proveniente de Guinea, que reivindicó la libertad de los esclavizados en Colombia. Ejecutado en Cartagena, 1621.

12 Dentro de las creencias yorubas, este equivale a un sacerdote.
} 
estudio, nos detendremos únicamente a examinar la manera como Zapata Olivella presenta y desarrolla la presencia de las serpientes en su obra literaria, sin realizar un análisis que contraste el valor simbológico de estas en otros contextos. En Changó, el autor colombiano nos presenta a las serpientes como un elemento que hace referencia a la naturaleza y, por ende, al Kintu. En la novela, la aparición de las serpientes se da dentro del marco narrativo ubicado en la primera parte de la novela, y se mantiene hasta la última. Zapata Olivella (2010) las introduce relacionándolas específicamente con Changó:

El hijo de Yemayá/ invencible guerrero/procreador de Orichas despierto de su sueño/una serpiente en cada mano/ mordiéndose las colas/ me mostraba,/ las serpientes de Tamin/ las serpientes mágicas/ vida y muerte inmortales/ símbolos del Muntu/en el exilio. (p. 66).
Desde el inicio de la novela, Zapata Olivella otorga a las serpientes el valor simbólico del Muntu en el exilio, atribuyéndole a una serpiente el valor de la vida y a la otra el de la muerte. Esta representación es dada a modo de presagio, pues la libertad es un objetivo que comprende muchos sacrificios y muertes de parte de los africanos. De este modo, vemos que en la primera parte de la novela titulada "Los orígenes"13, Zapata Olivella dota al lector de elementos que le servirán a modo de tabla de lectura/navegación a lo largo de la novela. En cuanto a los pasajes que hacen referencia a las serpientes, notamos que se encuentran íntimamente ligadas a un discurso de rebeldía y sublevación animados por los orichas Elegba y Changó: "¡Abobó Elegba, nudo fuerte/ reconoce a tu hijo/ Benkos Biohó, las dos serpientes/grabaste sobre su hombro!/¡Ábrele paso a Changó!" (Zapata Olivella, 2010, p. 173).

Dentro de este marco de ideas, observamos que las serpientes pueden ser consideradas como un recurso estilístico que Zapata Olivella utiliza igualmente con el fin de otorgar cierta jerarquía a sus personajes. Mencionaremos, por ejemplo, a Nagó, un ancestro africano que viaja en una nao hacia América, y quien será líder de la primera revuelta de prisioneros africanos en el barco "La nova India": "Sobre el hombro de Nagó se entrecruzaban las serpientes de Elegba. El kilumbu blanco supuso que era la cicatriz de una doble incisión abierta por el brujo de la tribu y prosiguió observando bocas y contando dientes" (Zapata Olivella, 2010, p. 88). Vemos también, que el valor significativo de las serpientes es un elemento desconocido para los "blancos", ${ }^{14}$ quienes las advierten cuando las miran, sin llegar a descifrar la carga que este distintivo encarna. Dado que son muchas las apariciones de serpientes en la novela, presentamos una tabla con los diferentes personajes que portan las serpientes y los momentos en que aparecen:

\footnotetext{
13 El nombre de este primer capítulo de la primera parte "Los orígenes" coincide con tres aspectos relevantes: el capítulo de apertura de la novela, una explicación mítica del origen de los orichas dentro de la cosmovisión del Muntu, y la causa por la cual los africanos son enviados a América, generando así un nuevo origen a nivel histórico y literario.

14 Así menciona también Zapata Olivella a los españoles.
} 


\begin{tabular}{|c|c|c|c|}
\hline Personaje & Rol en la novela & $\begin{array}{c}\text { Parte y capítulo en } \\
\text { el que aparece }\end{array}$ & Citas \\
\hline Nagó & $\begin{array}{l}\text { Ancestro africano, } \\
\text { líder de la revuelta en } \\
\text { la nao Nova India. }\end{array}$ & $\begin{array}{l}\text { Primera parte, } \\
\text { capítulo II. }\end{array}$ & $\begin{array}{l}\text { "El contramaestre sigue preocupado por la pérdida } \\
\text { de nuevas herramientas. Entramos en sospecha del } \\
\text { kru con la máscara de hierro. Sobre su hombro tiene } \\
\text { tatuadas dos serpientes y juro que se mueven debajo } \\
\text { de la piel" (p. 140). }\end{array}$ \\
\hline $\begin{array}{l}\text { Hijo de Sosa } \\
\text { Illamba }\end{array}$ & $\begin{array}{l}\text { Se le denomina el } \\
\text { Muntu Niño. }\end{array}$ & $\begin{array}{l}\text { Primera parte, } \\
\text { capítulo III. }\end{array}$ & $\begin{array}{l}\text { "Desangrada, el hijo le nada entre las piernas... En } \\
\text { mitad de su pecho, mordiéndose los rabos, pudimos } \\
\text { ver que se movían las dos serpientes de Elegba" (p. } \\
\text { 145). }\end{array}$ \\
\hline $\begin{array}{l}\text { Benkos } \\
\text { Biohó }\end{array}$ & $\begin{array}{l}\text { Se convertirá en el rey } \\
\text { de los africanos en } \\
\text { Cartagena. }\end{array}$ & $\begin{array}{l}\text { Segunda parte, } \\
\text { capítulo II. }\end{array}$ & $\begin{array}{l}\text { “iSobre su hombro se abrazan las dos serpientes del } \\
\text { poderoso Elegba...!” (p. 155). } \\
\text { "El último gesto del padre, todavía bajo la mirada } \\
\text { del superior, fue trazar el signo de la cruz sobre el } \\
\text { hombro izquierdo del pequeño. Debió sentir que el } \\
\text { fuego de las serpientes le quemaba sus dedos porque } \\
\text { aterrorizado levanta la mano”. (p. 171). } \\
\text { “¡Abobó Elegba, nudo fuerte/ reconoce a tu hijo / } \\
\text { Benkos Biohó, / las dos serpientes/ grabaste sobre } \\
\text { su hombro!/ ¡Ábrele paso a Changó!” (p. 173). }\end{array}$ \\
\hline $\begin{array}{l}\text { Simón Bo- } \\
\text { lívar }\end{array}$ & $\begin{array}{l}\text { Relato sobre la lucha } \\
\text { de mestizos y la } \\
\text { libertad. }\end{array}$ & $\begin{array}{l}\text { Cuarta parte, capí- } \\
\text { tulo I. }\end{array}$ & $\begin{array}{l}\text { "Las aguas se oscurecieron. En el fondo de la batea } \\
\text { dos serpientes se devoran las colas sin que la madre } \\
\text { Yemayá logre separarlas. Son las sombras de tu amo } \\
\text { Simón y del almirante José Prudencio. Combatirán } \\
\text { juntos por la independencia de sus países pero no se } \\
\text { ponen de acuerdo para darnos la libertad" (p. 319). }\end{array}$ \\
\hline Agne Brown & $\begin{array}{l}\text { Líder afrodescendiente } \\
\text { que reivindica el Mun- } \\
\text { tu en Estados Unidos. }\end{array}$ & $\begin{array}{l}\text { Quinta parte, capí- } \\
\text { tulo I. }\end{array}$ & $\begin{array}{l}\text { "Intuirás la forma de la mancha: dos serpientes } \\
\text { mordiéndose las colas. Tratas de aliviar tu desazón } \\
\text { con la piadosa idea de que te ahogas en una pesadi- } \\
\text { lla. El agua tibia, la apertura de las cortinas, la luz } \\
\text { de la lámpara apenas son anuncios de la mañana } \\
\text { inundando el cuarto y entonces oíste que de la ca- } \\
\text { lle sube ese inconfundible vocerío de la ciudad que } \\
\text { despierta" (p. 444). } \\
\text { "Te acompañé hasta la capillita perdida en la barria- } \\
\text { da. Desde mucho antes de marcarte con las serpien- } \\
\text { tes de Legba te sigo los pasos" (p. 447). } \\
\text { "--Las serpientes de Legba... - exclamó. — ¡Para } \\
\text { renacer hay que morir!” (p. 452). } \\
\text { "Me alzo aún más manteniendo firmes los hombros. } \\
\text { Las serpientes se revolvían mientras las hebras en- } \\
\text { sortijadas caen sobre mi cuerpo" (p. 466). }\end{array}$ \\
\hline
\end{tabular}


A lo largo de la novela, constatamos que las serpientes representan un signo inequívoco del oricha Elegba. Este símbolo operará como un elemento que actúa de manera involuntaria en quienes lo poseen: constatamos que, en Nagó dan la impresión de moverse bajo la piel; en Benkos, tienen la propiedad de calentarse al percibir la mano de Pedro Claver; en Agne, se revuelven, cuando esta va a prisión. Así, estas serpientes incorporadas exhiben diversas manifestaciones físicas que intuyen la presencia hostil del enemigo. Las clasificamos dentro del Kintu, puesto que, si estas son un símbolo de los orichas, conservan la calidad de seres vivos, guardando evidentemente algunos rasgos de orden animal, como el movimiento.
Además de la inclusión de animales y plantas en la narración, Zapata Olivella crea una serie de neologismos que se refieren al Kintu, evidenciando la permeabilidad tanto como la adaptabilidad de estos a su lenguaje literario: "Hombres-Bosques" (p. 52), "Padre-Fuego-Sol", "Hijos-Luceros", "Hermanas-Estrellas" (p. 63), "Torosol" (p. 64), "Truenoluz" (p. 70), "toroluna" (p. 91). Observamos que el escritor colombiano explora, mediante su novela, una transformación lingüística que evoca la incidencia de la naturaleza, una reflexión que nos invita a la vez a pensar al hombre como un elemento que necesita de la naturaleza, y que ve en ella un elemento profundo de familiaridad y de nexos con sus orígenes africanos. A conti- nuación, presentaremos la categoría Hantu en la novela, un eje amplio que nos permitirá comprender de una mejor manera las bifurcaciones histórico-temporales que componen Changó.

\section{Hantu}

Jahn (1963) percibe esta categoría simplemente como "lugar y tiempo"15, considerando "oriente" y "ayer" como ejemplos que plasman el Hantu (p. 19). En Changó, abordaremos el Hantu, orientando nuestra reflexión hacia el tiempo histórico, así como a los escenarios asociados a dichos momentos. De este modo, sugerimos cinco grandes momentos y espacios significativos en la novela:

\begin{tabular}{|l|l|l|}
\hline \multicolumn{1}{|c|}{ Siglo } & \multicolumn{1}{c|}{ Lugar } & \multicolumn{1}{c|}{ Suceso Significativo } \\
\hline 1. XVI & África & Africanos a punto de partir al exilio \\
\hline 2. XVII & Cartagena & Inquisición y resistencia de los esclavizados \\
\hline 3. XVIII & Haití & Revolución haitiana \\
\hline 4. XIX & Latinoamérica & Emancipación y mestizaje \\
\hline 5. XX & Estados Unidos & Lucha por la igualdad de derechos civiles \\
\hline
\end{tabular}

Zapata Olivella desarrolla su obra literaria dentro de un orden cronológico evolutivo que gira en torno al anhelo que tienen los africanos con el fin de romper la maldición de Changó. Advertiremos que la aproximación a la libertad es vista a partir de una perspectiva americana que se desarrolla en diversos focos espaciales que constituyen ejes complejos de revueltas de afrodescendientes. Los diferentes ejes o iniciativas rebeldes, pasan por un proceso de germinación, organización y acción, y se encuentran ligados a un lugar y un momento histórico deter- minado. Dentro de este orden de ideas, en la primera y segunda parte de la novela, el tiempo histórico opera implícitamente, sin que haya referencias concretas, salvo por una que encontramos en el tercer capítulo de la primera parte y que hace referencia al "Libro de Derrota",

15 El Hantu es descrito desde esta misma perspectiva por Mbiti. John (1969) en: African Religions \& Philosophy, y Aliko Songolo (1991) en: Muntu Reconsidered: From Tempels and Kagame to Janheinz Jahn. 
el diario de los opresores que transportaban a los africanos en las naos:

Dejo constancia en este cuaderno de bitácora de lo sucedido en la factoría de Nembe y de cuanto acontezca en los días por venir de esta travesía que se inicia con tan inesperados y trágicos presagios. A los diecisiete días de marzo del año mil quinientos cuarenta, a bordo de la nao Nova India. (Zapata Olivella, 2010, p. 108).

La cita anterior se enmarca dentro del capítulo "La trata", un relato presentado a dos voces; la de los negreros y la de los prisioneros africanos. En este pasaje, observamos que el diario de los opresores comienza relatando la muerte de quien sería el capitán del barco. De este modo, 1540 marcará el inicio del viaje hacia América desde la perspectiva de los europeos, mientras que, para los africanos de Changó, el inicio de este surge desde el momento en que son capturados: "Hoy es el día de la partida/ cuando la huella no olvidada/ se posa en el polvo del mañana... Hoy enterramos el mijo/ la semilla sagrada/ en el ombligo de la madre África/ para que muera se pudra en su seno /y renazca en la sangre de América" (Zapata Olivella, 2010, p. 45). Observamos que, en lo que concierne al viaje dentro del relato de los africanos, no hay una fecha específica sino simplemente una alusión al tiempo mediante el adverbio demostrativo "hoy" y el nombre masculino "mañana". Vemos de este modo que el tiempo para los africanos en la novela, es un agente impreciso que deambula entre la evidencia cruel de la separación, la trata y la esperanza de la lucha y unión de un marco espacial que une al continente africano y al americano.

En la segunda parte de la novela, vemos que una vez en Cartagena, el grupo heterogéneo de africanos continúa sus iniciativas rebeldes en busca de la emancipación. Para ello, será necesario aunar ese propósito bajo el carácter determinante y afro-reivindicativo de Benkos Biohó: "Eres el escogido de Changó para iniciar la rebelión del muntu. Tu grito resonará en otras voces, en otras vidas, donde quiera que la loba blanca pise la sombra de un negro." (Zapata Olivella, 2010, p. 228). La aparición de Benkos en la novela introduce una crítica a lo que la Inquisición significa para los africanos y sus creencias: "Las esclavas y esclavos se reúnen en las puertas, alegres, sin ni siquiera sospechar que los dobles de campana les estaban anunciando la guerra santa contra sus orichas, chivos y gallos embrujados" (Zapata Olivella, 2010, p. 176). Con estos ejemplos, hemos visto brevemente que además de los elementos de tiempo y espacio que el Hantu contempla, Zapata Olivella utiliza esta categoría como denuncia de la actitud inquisidora de la fe católica, y defensa de las creencias africanas.

Nos aproximamos ahora a Haití, otro escenario simbólico de la libertad para los afrodescendientes en América. A partir de la participación de personajes como Dutty Bouckman, François Mackandal o Toussaint L'Ouverture, que comprenden un lapso de tiempo entre 1791 y 1804 . De tal modo, resaltaremos la revolución haitiana como iniciativa rebelde predominante de la tercera parte de la novela: "en la noche de la esclavitud /Rotas las cadenas, libre, /cada vida/ cada muerte/ nos acercan a Changó" (Zapata Olivella, 2010, p. 263). Dicha iniciativa rebelde trae la muerte a un gran número de africanos y mestizos quienes, mediante la sublevación, se acercan a Changó. A partir del "tiempo" y "espacio" como elementos globales del Hantu, constatamos que, en Changó, Zapata Olivella explora esta categoría como otra posibilidad de ver la Historia y momentos específicos de la lucha de los africanos en América:

La historia de la República de Haití para los olvidadizos escribas de la loba ${ }^{16}$ será siempre la masacre de los negros fanatizados por el odio contra sus herma-

16 En la novela, se refiere a los colonizadores y opresores europeos. 
nos blancos, nunca el genocidio de los esclavistas contra un pueblo indefenso. (Zapata Olivella, 2010, p. 274).

La cuarta parte de Changó -"Las sangres encontradas"-, se encuentra compuesta por cuatro capítulos: "Simón Bolívar: memoria del olvido", "José Prudencio Padilla: Guerras ajenas que parecen nuestras", "El Aleijadinho: Donde quiera que tus manos sin dedos dejen la huella de tu espíritu" y "José María Morelos: El llamado de los ancestros olmecas". Podemos afirmar que, el contexto histórico de la cuarta parte de la novela nos ubica principalmente en el marco de guerras de independencia hispanoamericanas ocurridas a comienzos del siglo XIX. Simón Bolívar, José Prudencio Padilla y José María Morelos insisten en la fuerza que reside en el mestizaje como resultado efectivo en los procesos de emancipación de España: “iColombianos! ¡Nos aguarda la libertad o la esclavitud! ¡ No podemos esperar merced de un enemigo que ha dado repetidas muestras de ser sanguinario y cruel!" (Zapata Olivella, 2010, p. 356). En este ejemplo específico, situado en la guerra de independencia colombiana, el almirante Padilla incita a sus tropas a la resistencia, evocan- do el carácter despiadado del enemigo al que se enfrentan. En el mismo sentido, vemos que el deseo de emancipación requiere una gallardía que palpita en los africanos como en los mestizos, mulatos y zambos. Así, en esta parte del libro, Zapata Olivella (2010) manifiesta una suerte de antítesis al sistema de castas coloniales, positivizando el mestizaje:

Mulato y zambo a la vez, tengo la fiebre africana en los ojos y la sombra india en mi alma. Brujo, destruyo al enemigo con la vista antes de alcanzarlo con las balas. Vicente Guerrero es mi nombre porque en la guerra siempre fui protegido por Quetzalcóatl y Changó. (p. 428).

Desde el punto de vista del Hantu, Zapata Olivella presenta una lectura afro-céntrica de la independencia latinoamericana, destacando la fuerza de la alianza de los mestizos con los afro-descendientes en diferentes países y en diferentes épocas. El tiempo y el espacio son factores a partir de los cuales el escritor demuestra la manera como las raíces africanas renacen para seguir combatiendo constantemente.
En la última parte de la novela, Zapata Olivella ubica la narración en Estados Unidos, dentro del marco histórico de la segregación hacia los afrodescendientes; específicamente, el periodo que comprende el fin de la esclavitud hasta los 1960s. En el primer capítulo de esta parte, encontramos a Agne Brown quien siendo una niña debe enfrentarse al impacto de ver a su padre ahorcado: "Por aquellos días el reverendo Robert me adoptó como su hija a partir del instante en que me tapara los ojos frente al cadáver colgado de mi padre" (Zapata Olivella, 2010, p. 444). El personaje ficticio Agne Brown explora detalladamente la problemática de iniquidad hacia los afrodescendientes entretejiendo su propia historia con la de líderes de descendencia africana, tales como Malcom X, ${ }^{17}$ Marcus Garvey ${ }^{18}$ o Nat Turner, ${ }^{19}$ entre otros. En Nueva York, Agne profesa y defiende sus creencias, dándole al Muntu el estatus de religión. Lo anterior le ocasiona problemas de orden legal, puesto que es acusada de ser:

Predicadora de un nuevo culto detenida por prostitución. La señorita Agne Brown, antropóloga de la Universidad de Columbia, convicta de practicar públicamente la poliandria.

\footnotetext{
Activista estadounidense (1925-1965) defensor de los derechos de los afrodescendientes.

Líder afrodescendiente jamaiquino, fundador de la Asociación Universal para la Mejora del Hombre Negro.

Esclavizado estadounidense, líder de la resistencia en Southampton, Virginia.
} 
No se sabe si se trata de un novedoso sistema de prostitución o de una depravación mística... Ha sido encarcelada. (Zapata Olivella, 2010, p. 467).

En esta última parte de la novela, no encontramos fechas específicas; no obstante, después de recuperar su libertad, Agne asiste al funeral de Malcom X, hecho histórico que tiene lugar el 27 de febrero de 1965 en el Templo de la Fe, en Harlem, Nueva York. En la novela, durante el funeral de Malcom X, los orichas Ochosí, ${ }^{20}$ Elegba y Changó se aparecen para manifestar la ira de este último oricha, quien reclama coléricamente a los afrodescendientes por tardarse tanto en alcanzar su libertad.

En Changó, el tiempo es una categoría que evade frecuentemente la precisión obsesiva de la Historia. Leer la novela a partir de la perspectiva del Hantu, permite comprender que, sin recurrir a fechas precisas, Zapata Olivella emprende una reconstrucción histórica de los hechos libertarios más significativos. Tal como analizamos anteriormente en el Kintu, Zapata Olivella introduce neologismos que permiten hacer un seguimiento del Hantu desde una nueva comprensión del tiempo: “el ayermañana" (Zapata Oli- vella, 2010, p. 146, 274) "las nochesdías" (Zapata Olivella, 2010 , pp. 277, 457), "los díasnoches" (Zapata Olivella, 2010, p. 227), "El pájaronoche" (Zapata Olivella, 2010, p. 13). A través de estas reconstrucciones lingüísticas, Zapata Olivella explora el tiempo en la novela desde un punto de vista creador-literario, plasmando en la narrativa la manera como algunos conceptos opuestos como el "día" y la "noche", o el "ayer" y el "mañana" se funden en una sola unidad lingüística para dar espacio a nuevas interpretaciones del tiempo, que van de la mano con las principales características del Hantu tanto como con la visión totalizadora del Muntu. De este modo, en Changó, el tiempo es un concepto deslizable, adaptable, maleable $\mathrm{y}$ transgresor que se mantiene abierto, que dialoga constantemente con los diversos elementos que componen la novela. Pasaremos ahora al Kuntu, delineando los principales rasgos de esta categoría filosófica bajo los elementos literarios de Changó.

\section{Kuntu}

Jahn (1963) afirma que el Kuntu es una categoría que tiene que ver con el estilo, la belleza, el ritmo, la calidad y la cantidad. Kagame lo relaciona con la manera de ser, mientras que otros como Henrique Cunha (2010) sostienen que el Kuntu tiene que ver con las cualidades subjetivas, como por ejemplo la inteligencia. Al respecto, notamos que Zapata Olivella ilumina a sus personajes con varios rasgos, relacionándolos frecuentemente con los orichas. En esta sección, exploraremos el Kuntu dentro del marco del carácter de los personajes. Particularmente, orientaremos nuestra reflexión hacia la manera como los designios de los orichas intervienen en la construcción y consolidación del pensamiento de los personajes en Changó.

En el primer capítulo de la primera parte de la novela, vemos que Ngafúa toma la iniciativa de guardar la memoria de los orichas para cultivarla en América: "¡Changó!/ Voz forjadora del trueno./ ¡Dame tu palabra saliva/ dadora de la luz y de la muerte/ sombra del cuerpo/ chispa de la vida!" (Zapata Olivella, 2010, p. 70). Además de esto, en Ngafúa encontramos rasgos como la perseverancia y la tenacidad. Prueba de ello es su carácter durante el viaje de África a América. Ngafúa es acusado de ser responsable de incitar la rebeldía en la nao que transporta a los africanos al nuevo mundo, por consiguiente, es torturado con el fin de que denuncie a sus cómplices: "Mantienen acorralado a Ngafúa. Le azotaban y riegan

20 Oricha guerrero de la Caza, se relaciona con la justicia y los perseguidos. 
sal y pólvora sobre sus heridas. La loba mayor ladra, pidiéndole que denuncie nuestro plan y solo escuchamos su invitación a que resistamos." (Zapata Olive1la, 2010, p. 135). La valentía y la gallardía ante el dolor serán pruebas fehacientes del carácter sólido de Ngafúa. Contrario a la impasibilidad que muestra ante sus opresores, sabremos que, ante los africanos y sus descendientes en América, Ngafúa desarrolla un carácter profético y solidario que trasgrede constantemente la muerte: "soy Ngafúa, mensajero de Changó. Te hablo con los ojos invisibles de tus ancestros aquí presentes..." (Zapata Olivella, 2010, p. 443). En la cita anterior, Ngafúa se presenta ante Agne, personaje fundamental de la quinta parte de la novela. Según las pistas de Changó, Ngafúa hace el viaje con los africanos hacia América en el siglo XVI; sin embargo, constatamos en la quinta parte de la novela, -incluso más de tres siglos después en el relato- que su carácter mantiene los mismos rasgos de intermediario $\mathrm{y}$ de apoyo a quienes buscan redimir a los afrodescendientes oprimidos.

Por otra parte, examinaremos el carácter de Benkos Biohó en "El Muntu Americano" segunda parte de la novela. El vaticinio del nacimiento de Benkos surge dentro del marco de vindicación de agravios que los africanos padecen bajo el implacable poder perseguidor español:

-¡Oíd, oídos del muntu! ¡Oíd! Aquí nace el vengador, ya está con nosotros el brazo de fuego, la muñeca que se escapará de los grillos, el diente que destroza las cadenas... Escuchen: el protegido de Elegba trae sangre de príncipe. Nace entre nosotros, será nuestro rey. (Zapata Olivella, 2010, p. 155).

En Benkos, surge una serie de rasgos preestablecidos que operan como un presagio libertario. Por otra parte, encontramos que su fuerza sexual desde temprana edad marca su parentesco con Changó, oricha de la virilidad: "Todavía es un niño pero ya era un viejo. Doce años tiene y ya levantaba su verga de toro" (Zapata Olivella, 2010, p. 172). ${ }^{21}$ Finalmente, la proximidad a la religión católica, sin que esta logre persuadirlo, sustenta asimismo la firmeza y la lealtad de su carácter:

En estas correrías del padre Claver, el pequeño rey Benkos era el sacristán de sus bautizos, testigo de los matrimonios... Nunca le dije no bebas de esa corriente. Sé que en una tinaja caben muchas aguas pero solo la fresca se va al fondo mientras la inútil sube y se derrama. (Zapata Olivella, 2010, p. 167).

Luego de su coronación, Benkos sustenta su punto de vista a Claver, quien inútilmente intenta convencerlo de arrepentirse recordándole la formación cristiana que ha recibido:

- Sepa padre - le dijo con resentimiento - que poca diferencia hace usted en las obras del Señor. Al burro le hizo torpe y bien hace en callar, pero a los hombres nos dio entendimiento. Si yo fuera un asno no aspiraría a tener una corona aunque fuera de papel. La voz de Satanás no le hubiese dejado tan pálido. Le echó la bendición y afligido, me dice: -Vámonos Sacabuche, tengo que orar por este réprobo. (Zapata Olivella, 2010, p. 205).

Estas no son razones suficientes para debilitar el carácter del recién nombrado rey, quien se empeña en continuar fiel a sus creencias africanas más allá de su muerte.

En lo que concierne "La Rebelión de los Vodús", tercera parte de la obra literaria de Zapata Olivella, encontramos un pasaje

$\overline{21} \quad$ “Te nombro, Changó, /padre de las tormentas/ con tu verga de toro/relámpago descomunal." (Zapata Olivella, 2010, p. 51). 
en el que el escritor colombiano sintetiza las cualidades de los héroes afrodescendientes de la revolución haitiana:

Changó fue nombrando a sus generales: - Mackandal, te hago mariscal. Vengarás la sangre de los ekobios torturados. A Bouckman le entregó el fuego para que incendiara los cañaverales y trapiches. - iA ti, Toussaint L'Ouverture, te doy las llaves de Elegba! ¡Aun después de muerto, serás la gran abertura de la libertad! Así, conociendo la inteligencia y el coraje de cada uno de sus guerreros, les enriquece para sus hazañas. (Zapata Olivella, 2010, p. 285).

Tal vez este sea el pasaje donde se perciba de una manera suficientemente clara las características del Kuntu. Observamos que Changó asigna a cada uno de sus generales una tarea especial para llevar a cabo durante la revolución haitiana. Prestamos especial atención a L'Ouverture, pues hay en él un elemento de motivación lingüística que lo relaciona y lo asemeja a Elegba, el oricha que abre los caminos. La "abertura" de la libertad es una metáfora con la que Zapata Olivella sostiene el relato de los Vodús en Changó.

En lo que concierne a la cuarta parte de la novela, vemos que en el primer capítulo de "Las Sangres encontradas", existe una referencia que nos permite señalar el vínculo directo entre Changó y el carácter libertador que florece en Bolívar: "¿Qué significa ese remolino?... Rojas, amarillas, azules, el arco iris cabalga las nubes. - ¡Hipólita, míralas, cinco banderas! ¡Cinco banderas! ¡Por mandato de Changó, el varoncito que chupa tu leche será el libertador de muchas naciones!" (Zapata Olivella, 2010, p. 318). Vemos que son varios los casos en que Zapata Olivella toma datos históricos para transformarlos a literatura y ponerlos al servicio de la revuelta de las negritudes. De este modo, la misión libertaria de Bolívar se encuentra designada anticipadamente por Changó y tendrá como testigo a Hipólita, la nodriza afrodescendiente de Bolívar.

En el caso del almirante José Padilla, los orichas también han dispuesto hacer de él un apasionado por el mar:

No habías nacido, pensamiento eran las sangres de tus ancestros, cuando Odumare te concibe en el vientre de tu primera madre. Changó me nombró tu protector y desde entonces, tu destino marinero es semilla que siembro y multiplico hasta traerte aquí. (Zapata Olivella, 2010, p. 331).
En la cita anterior, notamos que José Padilla se encuentra predestinado a ser marinero; dejando claro que Odumare como "supremo dios omnipotente" (Zapata Olivella, 2010, p. 661) ha trazado planes específicos para Padilla y que estos se han gestado con bastante anticipación; a través de los ancestros de Padilla se estaba gestando no solo la voluntad de Odumare, sino también el carácter del rebelde y valiente almirante $\mathrm{Pa}$ dilla.

Finalmente, abordamos a Agne Brown, resaltando que de todos los personajes de la novela, es a ella a quien Changó le ha otorgado el reconocimiento y la responsabilidad más considerable del relato: "Changó, entre todos los ekobios, te ha escogido a ti: mujer, hija, hermana y amante para que reúnas la rota, perseguida, asesinada familia del muntu en la gran caldera de todas las sangres" (Zapata Olivella, 2010, p. 443). Para que esto suceda, Agne debe nutrir su carácter con diversas y dolorosas experiencias: de un lado, su vida se convierte en testimonio de su lucha: Hija de un padre asesinado, segregada en el colegio por ser afrodescendiente, socialmente rechazada, acusada y conducida a prisión por rendir culto a Changó. Notamos que su carácter invulnerable se fortalece a partir de múltiples testimonios que llegan a ella desde el pasado: "Agne Brown, soy Ngafúa, mensajero de Changó. 
Te hablo con los ojos invisibles de tus ancestros aquí presentes:" (Zapata Olivella, 2010, p. 443). Agne es un personaje en el que converge el fruto del (re)nacimiento del Muntu en América; en ella se concentra la fuerza de las luchas afrodescendientes y mestizas que han contribuido desde diferentes espacios $\mathrm{y}$ diferentes temporalidades: "Era tu voz, Agne Brown. Tenías viejos acentos de ekobios a quienes solo he oído hablar aquí en la Casa de los Muertos. Benkos Biohó, Gunga Zumbi, el Aleijaidinho, L' Ouverture, José María Morelos, Bolívar, Nat Turner..." (Zapata Olivella, 2010, p. 545).

Agne Brown es un personaje determinante en la trama de Changó, dotado con el coraje y la impetuosidad de sus ancestros rebeldes.

Me dirijo a vosotros, ekobios que me escucháis. No a los blancos sordos. No vengo a predicar paciencia ni resignación ni vanas esperanzas: les anuncio el culto de la vida y las sombras que inspiran la rebeldía que hay en nosotros los negros. Más allá solo perdura el eco de los sueños. Pero oídlo bien, vida y rebelión no existen sin la presencia de los muertos. (Zapata Olivella, 2010, p. 448).
A través de Agne, así como de otros personajes, podemos ver cómo Zapata Olivella construye una estrategia específica con respecto a los personajes, que coincide con la perspectiva filosófica del Muntu. El autor desdibuja la silueta de un personaje principal para dar cabida a una pluralidad de personajes que se alterna a medida que avanza la novela. Los personajes se funden entre sí, entre el mundo de los hombres y el mundo de la divinidad para cuestionar la historia. El análisis de la novela a partir del Kuntu, permite ver que Zapata Olivella elige ciertos personajes de su obra para dotarlos con el carácter rebelde de determinados orichas, demostrando así que los dioses africanos se encuentran presentes, librando las guerras y sufriendo las angustias del ejército de Changó en América. Finalizaremos nuestro estudio con el Muntu, categoría que Zapata Olivella explora, otorgándole vida y palabra a la muerte.

\section{Muntu}

Tempels sostiene que el significado de la categoría Muntu se acerca más al término persona que a la simple traducción "hombre"; pues, con frecuencia este concepto se encuentra relacionado con la corporalidad, mientras que el término "persona" involucra aspectos que trascienden del plano corporal. En este orden de ideas, Tempels (2013) manifiesta también que, si bien el Muntu reside en un cuerpo visible, el cuerpo no es lo que hace al Muntu, sino las cualidades relacionadas con el ser. Además de lo anterior, "el Muntu o la persona es una fuerza suprema más poderosa que los animales, las plantas y los minerales". (Tempels, 2013, p. 61). De este modo, es posible deducir que esta categoría estudia al ser humano, abordando, entre otros, la correlación con los ancestros y los difuntos. Por su parte, Jahn (1963) sostiene que Muntu es una palabra Bantú ordinariamente traducida como "hombre" y que señala también a los dioses, a los ancestros y a los difuntos.

Los ancestros y los difuntos son elementos del Muntu que Zapata Olivella transforma en literatura. Nos cuestionaremos ahora: ¿Quiénes son los ancestros y en qué contexto aparecen en la novela? ¿Qué funciones tienen en el imaginario de Changó? ¿Cómo se suman las voces de los difuntos al relato literario de Zapata Olivella? Comenzaremos mencionando que, en Changó, Zapata Olivella presenta cinco ancestros: Ngafúa, Nagó, Olugbala, Kanuri Mai y Sosa Illamba.

Ngafúa es el primer ancestro que aparece en la novela. En el apartado anterior mencionamos que hará las veces de profeta del Muntu en América. Además de ello, aparece en repetidas oca- 
siones guiando a los soldados de Changó en América:

Lo cierto, Simón, es que soy Ngafúa, mensajero de Changó, tu protector en la guerra. Tomo mil formas, he estado contigo desde antes de nacer. Seré Hipólita para cerrar tus ojos. Vengo a prevenirte contra aquellos que escondidos en tu propia sangre buscan tu fracaso. (Zapata Olive1la, 2010, p. 315).

- Soy Ngafúa, mensajero de Changó en estas tierras. Sígueme, te llevaré a la morada de tus mayores. (Zapata Olivella, 2010, p. 407).

Zapata Olivella insiste constantemente en presentar a Ngafúa como el mensajero de los orichas; hay en él un matiz que roza con lo divino. Tiene además la capacidad de desdoblarse, transformarse y presentarse bajo otra apariencia física, por ejemplo, se transforma en Hipólita, la niñera de descendencia africana, esclavizada, de la familia de Simón Bolívar. Zapata Olivella toma el referente histórico de Hipólita, y lo literaturiza, con el fin de plasmar rasgos del Muntu en la novela. Por otra parte, en la segunda cita, Ngafúa se presenta ante José María Morelos, sacerdote militar líder de la independencia mexicana. El ancestro africano tendrá la misión formadora de fortalecer el carácter guerrero de Morelos. El uso del adjetivo posesivo en segunda persona, "tus", revindica la herencia africana que hace vibrar los ideales emancipadores del mestizo mexicano.

En el primer capítulo de la novela "Tierra de los ancestros", encontramos la primera referencia a Nagó, quien está ligado con el viaje y la navegación: "Que no falte ningún Ancestro/ en la hora de la gran iniciación/ para consagrar a Nagó/ el escogido navegante/ capitán en el exilio/ de los condenados de Changó" (Zapata Olivella, 2010, p. 45). Sin embargo, al igual que Ngafúa, la presencia de Nagó es retomada a lo largo de la novela. Su relación con la navegación surge a partir del rol que Nagó tiene para sublevar a los africanos de la nao negrera y su posterior naufragio en las aguas del atlántico:

Siempre que la luz y la sombra se unen, Nagó se echaba mar adentro con su barco en busca de náufragos. Recorrerá las rutas de los vientos, las mismas por donde andan las naos con sus cargamentos de esclavos para recoger a los ekobios muertos en la travesía. (Zapata Olivella, 2010, p. 151).

Tú sabías, madre Yemayá, que soy el protegido de Nagó. ¡Que su sombra cubra mi barco cuando cruce frente a las baterías enemigas! (Zapata Olivella, 2010, p. 354).

Este último pasaje de Changó hace referencia al almirante José Padilla, personaje histórico cuyo destino marinero en la novela está rodeado por las aguas viajeras de Yemayá, oricha femenina deidad de las aguas. Zapata Olivella se nutre de la Historia de Padilla modificando su discurso en la novela para crear un trinomio que englobara lo divino, lo ancestral y lo histórico.

Pasamos ahora a Olugbala, ancestro africano cuya presencia se advierte en "La trata" segundo capítulo de la primera parte de la novela. Olugbala es presentado como un africano robusto al que se le compara con la ballena y con la hormiga: "Su cuerpo de ballena ocupaba tres veces el espacio reservado a cualquiera de nosotros. No deja de observarme con la sonrisapájaro que ilumina su cabeza de hormiga" (Zapata Olive1la, 2010, p. 112). Vemos aquí que la ballena hace alusión a la grandeza corporal de Olugbala, idea que contrasta notablemente con la pequeñez de su cabeza de hormiga. De este modo, en Olugbala, grandeza y pequeñez encarnan los misterios de la profundidad del mar fusionados con la astucia laboriosa e incesante de la hormiga. Notamos que Zapata Olivella toma elementos del Kintu, para plasmar 
los rasgos que definen a este ancestro:

Durante la corta travesía, solo él pudo oír y escuchar la ballena invisible que seguía el barco: Ogún Olugbala, su ancestro protector aconsejándole la prudencia de la hormiga y esconder la pujanza del elefante que tienen sus brazos. (Zapata Olivella, 2010, p. 260).

Ogún Olugbala nos repite que la fortaleza de la hormiga reside en su constancia. Perdidos en la hojarasca, pequeñitos, iniciamos el desmoronamiento de la esclavitud. (Zapata Olive1la, 2010, p. 275).

El retrato de Olugbala y su misión como ancestro protector se encuentra íntimamente ligado al carácter de los animales con los que frecuentemente se le representa. La constancia es señalada a su vez como un componente pequeñito en el sentido en que puede ser casi imperceptible. De este modo, la rebelión de los esclavizados es metaforizada resaltando la manera como los pequeños esfuerzos redundarán en la desaparición de la esclavitud. Además del carácter trabajador de la hormiga, destacamos también el saber vivir en sociedad apuntando hacia un objetivo en común. En Changó, Olugbala es el ancestro de José María Morelos quien se trans- figura ante él, portando la voz de los oprimidos, y haciéndole saber que su puño se fortalecerá bajo su protección y la de los orichas.

En lo que concierne al ancestro Kanuri mai, -al igual que en el caso de los otros ancestros- su participación en la rebelión de la nao negrera. La presencia de este ancestro en la novela se encontrará estrechamente relacionada con las plagas, los mosqui-

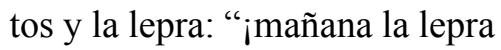
devorará tu rostro! Comidos los párpados y la nariz, tu cara será colmena de las moscas" (Zapata Olivella, 2010, p. 131). Con Kanuri mai, Zapata representa la enfermedad y la fealdad, como elementos que no interfieren con su calidad de ancestro; el desfigurado rostro de Kanuri mai no constituye un motivo de olvido dentro de la dimensión de los ancestros, pues mediante su ejemplo comprendemos que la enfermedad es otra dimensión del ser humano. En la novela, él será el protector del escultor brasilero Aleijadinho ante quien se presenta para hacerle saber:

- ¡Éía Aleijadinho, hermano del dolor, hermano soy tuyo! Igual que tú, vestí la capa del leproso. Déjame ser el fuego de tu cincel. Aunque nunca me reconocerás soy tu propia imagen, tu ancestro protector desde que fuiste sembrado en el vientre de la madre dos mil años atrás...-Soy Kanuri mai, nunca apartado de ti. Me esculpirás en los rostros de tus profetas, en las carnes desgarradas del buen Señor de Matozinhos, allí donde quiera que tu mano sin dedos dejó la huella de tu espíritu (Zapata Olive1la, 2010, p. 376).

La lepra tanto como la fealdad que esta causa, sumadas a la ancestralidad, caracterizan a uno de los personajes históricos que Zapata Olivella vuelve ficción en su obra, el escultor brasilero Antonio Lisboa -el Aleijadinho-. Zapata Olivella retoma en su novela la lepra, una enfermedad que padeció el Aleijadinho y que redujo drásticamente sus capacidades de esculpir: “-¡Fíjense! ¡Ya ni siquiera puedo agarrar nada! ¿Para qué me sirven estos dedos? Mas bien me estorban. Sin ellos, Mauricio, podrías atarme mejor el cincel y el martillo... Januario nunca quiso cortármelos" (Zapata Olivella, 2010, p. 404). Vemos en Changó, que el relato del Aleijadinho corresponde en gran parte a hechos reales; pues, en sus biografías se afirma que su ayudante le amarraba las herramientas a las manos para que pudiera continuar trabajando. Zapata Olivella retoma esos elementos e ilumina el carácter literario del Aleijadinho resaltando en él la pasión y el coraje como rasgos permanentes de la lucha que este lleva a cabo me- 
diante su obra artística. En la novela, la lepra no es un factor que genere una barrera entre el artista y las demás personas; al contrario, observamos que Zapata Olivella lo dota incluso de un estatus similar al de "un cristo negro" venerado y estimado por los suyos:

${ }_{-}$El Aleijadinho! - ${ }_{\text {¡El }}$ Aleijadinho! Negros y caboclos le depositaban granos de oro en lo hondo de sus heridas, le cuelgan cadenitas de plata labradas en los días de enfermedad. Los más fanáticos alargaban los dedos para humedecerlos en sus úlceras frescas. Cristo vivo, negro, comido por los dolores. Le gritan: — ¡Sálvanos Señor! ¡Nuestra esclavitud es más dolorosa que tus llagas! (Zapata Olivella, 2010, p. 400).

Finalmente, abordaremos a Sosa Illamba, ancestro femenino que en la difusión literaria del Muntu en América será percibida como nodriza, madre y protectora en quien los hijos de África encontrarán una figura afectuosa que aliviara sus angustias: "Sosa Illamba intenta inútilmente calmarles el rezongo como si se tratara del propio hijo que ya le nace en el vientre. Los abraza contra su pecho y les daba palmaditas en las nalgas para adormecerlos" (Zapata Olivella, 2010, p. 93). Veremos que su hijo nace en el mar mien- tras que ella, desangrada, permanece allí. Su hijo, "el niño muntu" es rescatado y llevado a las costas americanas según lo establecido por Changó:

- Hijo de Yemayá, semilla de los vivos, nademos hacia la orilla. La madre me lo entrega, mirándome con los ojos ya líquidos. Calor y sangre bañaban mi pecho y mis brazos. Chapoteando en la sentina, dejo que Elegba me muestre la abertura que conduce al mar de los vivos. De repente me quedo solo, rodeado de aguas. El muntu niño pegado a mi cuerpo, única compañía (Zapata Olivella, 2010, p. 146).

Como madre y vientre de la filosofía Muntu, Sosa representa también la fertilidad, pues incluso después de su muerte, su vientre sigue haciendo crecer a América:

Y en los surcos abiertos, la madre Sosa Illamba pare las semillas de sus hijos inagotables (Zapata Olive1la, 2010, p. 285).

Sosa Illamba los paría en lagunas, ríos y mares por encargo de la madre agua Yemayá (Zapata Olivella, 2010, p. 427).

Si bien los otros cuatro ancestros mencionados anteriormente, son masculinos, eso no indica que el rol de Sosa en la novela sea menos significativo; por el contrario, Sosa representa la posibilidad de preservación del Muntu en América, pues su proliferativo vientre se funde en las aguas de Yemayá, dándole un matiz humano y místico a la procreación y al carácter significativo y fecundante de la mujer.

Hasta aquí señalamos los ancestros principales de la obra, concluiremos este apartado mencionando la dimensión de los difuntos y su inclusión dentro del relato. La exploración del Muntu a partir de la perspectiva de los ancestros permite tener la idea de la vida del ser humano como una fuerza que hace posible su existencia después de una muerte física. En Changó, el vínculo entre vivos y muertos ocurre como un acontecimiento cotidiano. En el primer capítulo de la tercera parte de la novela, "Hablan los caballos y sus jinetes" encontramos como narrador a Toussaint L'Ouverture quien, tras haber luchado en Haití por la libertad de los suyos, es finalmente acusado de conspiración y condenado a prisión en Fuerte de Joux en una de las regiones más frías de Francia donde muere en 1803. Desde la penumbra de su ventana, L'Ouverture advierte la presencia de un gorrión: "Revoloteando por la ventanilla de la celda se posó sobre mi hombro. Mensajero de Ogún Ngafúa, vienes a traerme noticias de mi lejana isla. Los muertos solemos soñar también 
con imposibles." (Zapata Olive1la, 2010, p. 242). En el pasaje anterior, Zapata Olivella utiliza la voz de Toussaint L'Ouverture con el fin de profundizar tres aspectos: la soledad de su prisión en Francia, la nostalgia que representa estar lejos de su país y la posibilidad de soñar como resistencia al exilio y olvido al que él es sometido.

Vemos en la tercera parte de la novela, que el "vodú" se convierte asimismo en un elemento de reivindicación de la filosofía Muntu en Haití, dado que gracias a sus rituales, aparece la posibilidad de recordar el pasado para insistir en la importancia que ha representado la filosofía Muntu para los antepasados afrodescendientes: "Hablo por boca de mi caballo Bouckman antes de recorrer el largo camino: - Era el principio del muntu en esta isla... Cabalgo su cabeza, gobierno sus ojos y su lengua" (Zapata Olivella, 2010, p. 245). De este modo, en la novela, el "vodú" otorga voz a múltiples narradores quienes desde la muerte matizan la pluralidad del Muntu, cumpliendo a su vez una función pedagógica de resistencia que convoca a valorar el pasado, y por lo tanto a mantenerse unidos bajo la promesa de liberación del Muntu.

La muerte es una perspectiva que involucra diversas miradas y sensibilidades en la novela; surge como una confirmación de los diversos elementos que atan los hilos de la filosofía Muntu, entrecruzándose también con algunas voces históricas: "Después de muerto proseguí la guerra porque los caídos en combate somos elevados al rango de general en el Ejército de los Difuntos. Suministramos armas a Télémaque Conga." (Zapata Olivella, 2010, p. 254). En la novela, Bouckman continúa con ahínco las batallas que ha de dejado en vida, desde la muerte ahora general de los difuntos, este personaje continúa impulsando sus guerras con el ardor que Changó puso en su puño. Al respecto, Zapata Olivella (citado en Captain-Hidalgo, 1985) sostiene:

Yo creo plantear en mi novela un nuevo aspecto del realismo literario: la revalorización mítica de la historia para que sirva de instrumento de lucha para los vivos a partir de la experiencia de los muertos. Siempre la historia fue mitificada por las clases dominantes... pero la concepción de la filosofía africana, base de mi inspiración literaria dinamiza este concepto; pues considera a los difuntos (ancestros) y vivos como una familia integrada "muntu", ligada y actuante (p. 30).

En síntesis, observamos que el Muntu en la novela es un término que supera la dimensión de persona planteada por Tempels y Jahn, puesto que, a partir de las cualidades relacionadas con el ser, Zapata Olivella insiste en la articulación del eje persona-ancestros-vida-muerte. La posibilidad de estudiar el Muntu desde esta perspectiva, nos permite considerar que Zapata Olivella pone estas relaciones fluidas al servicio de la revolución de las negritudes, generando así una relectura de un conjunto de elementos históricos que supone a perspectiva de las negritudes y sus luchas. De este modo, es posible concebir el Muntu en Changó como un gran "ser" múltiple compuesto por diversos trozos de existencia, y diferentes temporalidades; un ser cuyo rostro y pasado muta constantemente adaptándose a los retos de la diáspora africana en América.

\section{A modo de conclusión}

Leer Changó desde las categorías de la filosofía Muntu, nos permite una comprensión de sus elementos estéticos tanto como de la manera en que estos se encuentran articulados a la filosofía africana. En la novela, la filosofía Muntu se convierte en una carta de navegación que sitúa al lector en los diversos contextos históricos que propiciaron la emancipación de las negritudes en América. Así, mediante los hilos del Muntu, Zapata Olive1la fusiona las diversas luchas lideradas por afrodescendientes elevándolas también a un plano mítico del que se sirve el escri- 
tor colombiano para estructurar y organizar las cinco partes que componen: "Los orígenes", "El Muntu americano", "La rebelión de los vodús", "Las sangres encontradas" y "Los ancestros combatientes".

Bajo esta misma perspectiva, la filosofía africana del Muntu se convierte en un elemento de conexión de voces del pasado que Zapata Olivella utiliza con el objetivo de tejer y reconocer al sujeto africano mediante la literatura:

Quería escribir la epopeya de los cincuenta millones de africanos y de sus descendientes puros, mulatos y zambos bajo sus esclavizadores... para contar estas historias necesitaba un lenguaje común que no fuera el de los amos... No más "yo", no más “tú", no más "él”. Sino las mil voces americanas conjugando el "nosotros". (Zapata Olivella, 1987, p. 2).

De este modo, la filosofía Muntu nos permite explorar la porosidad de los personajes de Changó, así como las diferentes categorías como unidades discursivas, filosóficas, históricas y culturales; unidades viajantes, palpitantes y común-icantes que nos acercan a una cosmovisión globalizadora e incluyente cuyo eje se ubica en África, continente frecuentemente olvidado que también hace parte de nuestra historia y, por lo tanto, de nuestra literatura.
Finalmente, mencionaremos que la filosofía Muntu en la novela, se convierte en una especie de rizoma vibrante, una gran raíz viva que muta constantemente permitiendo el contacto entre los personajes, los orichas y los humanos, los vivos y los muertos, los elementos naturales tanto como el tiempo y el espacio que aparecen en la novela, poniendo estos elementos al servicio de la causa negra, de la abertura de la libertad de los afroamericanos, de la igualdad y de una apuesta por un "no" al olvido y un "sí" a la memoria, pero a la memoria filosófica y mítica africana; al desafío que supone el (re)nacimiento del Muntu en América y el largo camino que a los hijos de Changó aún queda por construir.

Ahora embárcate en la lectura y deja que Elegba, el abridor de caminos, te revele tus futuros pasos ya escritos en las Tablas de Ifá, desde antes de nacer. Tarde o temprano tenías que enfrentarte a esta verdad: la historia del hombre negro en América es tan tuya como la del indio o la del blanco que lo acompañarán a la conquista de la libertad de todos.

(Zapata Olivella, 1987, p. 36) 


\section{Referencias}

Captain-Hildago, Y. (1985). Conversación con el doctor Manuel Zapata Olivella. Afro-Hispanic Review, $4(1), 26-32$.

Cunha Júnior, H. (2010). Ntu. Revista Espaço Acadêmico, (108), 81-92.

Irwin, R., \& Szurmuk, M. (2009). Diccionario de estudios culturales latinoamericanos. México, D.F.: Siglo XXI Editores.

Jahn, J. (1963). Muntú: Las culturas neoafricanas. (J. Reuter, Trad.) México: Fondo de cultura económica.

Mbiti, J. S. (1969). African Religions \& Philosophy. Londres: Heinemann.

Montenegro De la Hoz, N. (2012). Huellas de africanía y liberación como propuesta ideológica en Changó, el gran putas. La palabra, (20), 77- 87. Recuperado de http://revistas.uptc.edu.co/revistas/index.php/la_palabra/article/view/953/953.

Montenegro De la Hoz, N. (2014). Changó, el Gran Putas: Formas de Resistencia e Identidad Esclavizada en los Estudios Poscoloniales. La palabra, (24), 59- 66. Recuperado de http://revistas.uptc. edu.co/revistas/index.php/la_palabra/article/view/2501/2360.

Songolo, A. (1981). Muntu Reconsidered: From Tempels and Kagame to Janheinz Jahn. Ufahamu: A Journal of African Studies, 10 (3), 92-100.

Zapata Olivella, M. (1987). Memoria de la palabra. Revista de estudios colombianos, (2), 1-2.

Zapata Olivella, M. (2010). Changó, el gran putas. Bogotá: Ministerio de Cultura.

Zapata Olivella, M. (2002). El árbol brujo de la libertad. Buenaventura: Próculo Alberto Ramírez, William Mina Aragón. 